\title{
Diagnosis and Treatment of Idiopathic Normal Pressure Hydrocephalus
}

\author{
Michael A. Williams, MD, FAAN; Jan Malm, MD, PhD
}

\begin{abstract}
Purpose of Review: This article provides neurologists with a pragmatic approach to the diagnosis and treatment of idiopathic normal pressure hydrocephalus (iNPH), including an overview of: (1) key symptoms and examination and radiologic findings; (2) use of appropriate tests to determine the patient's likelihood of shunt responsiveness; (3) appropriate referral to tertiary centers with expertise in complex iNPH; and (4) the contribution of neurologists to the care of patients with iNPH following shunt surgery.

Recent Findings: The prevalence of iNPH is higher than previously estimated; however, only a fraction of persons with the disorder receive shunt surgery. iNPH should be considered as a diagnosis for patients with unexplained symmetric gait disturbance, a frontal-subcortical pattern of cognitive impairment, and urinary urge incontinence, whose MRI scans show enlarged ventricles and whose comorbidities are not sufficient to explain their symptoms. Physiologically based tests, such as the tap test (largevolume lumbar puncture) or temporary spinal catheter insertion for external lumbar drainage with gait testing before and after CSF removal, or CSF infusion testing for measurement of CSF outflow resistance, can reliably identify patients who are likely to respond to shunt surgery. Properly selected patients have an $80 \%$ to $90 \%$ chance of responding to shunt surgery, and all symptoms can improve following shunt surgery. Longitudinal care involves investigating the differential diagnosis of any symptoms that either fail to respond to shunt surgery or that worsen after initial improvement from shunt surgery.

Summary: Neurologists play an important role in the identification of patients who should be evaluated for possible iNPH. With contemporary diagnostic tests and treatment with programmable shunts, the benefit-to-risk ratio of shunt surgery is highly favorable. For more complex patients, tertiary centers with expertise in complex iNPH are available throughout the world.
\end{abstract}

Continuum (Minneap Minn) 2016;22(2):579-599

\section{INTRODUCTION}

Idiopathic normal pressure hydrocephalus (iNPH) is the most common form of hydrocephalus in adults. Patients develop a syndrome characterized by dilated cerebral ventricles in combination with impaired gait, cognition, and urinary control (urgency and incontinence). The only effective treatment for iNPH is a CSF shunt, usually configured between the lateral ventricle and the abdomen (ventriculoperitoneal [VP] shunt). ${ }^{1}$ Between $60 \%$ and $80 \%$ of patients improve following shunt surgery. The average age of onset is about 70 years, and men and women are affected in equal numbers. In a population-based study from western Sweden, the prevalence of iNPH was estimated at $0.2 \%$ (200

\author{
Address correspondence to \\ Dr Michael A. Williams, \\ University of Washington \\ Medical Center, Department of \\ Neurology, 1959 NE Pacific St, \\ Box 356470, Seattle, WA 98195 , \\ maw99@uw.edu. \\ Relationship Disclosure: \\ Dr Williams serves on the \\ technical advisory board for \\ and holds stock options in \\ Aqueduct Critical Care, Inc \\ and has received personal \\ compensation and travel \\ expenses as a lecturer \\ for Codman Neuro, Canada. \\ Dr Williams has received \\ research support from the \\ National Space Biomedical \\ Research Institute as principle \\ investigator of study \\ SMST02801, comparing the \\ continuous noninvasive and \\ invasive intracranial pressure \\ management therapies, and as \\ co-investigator of study \\ CA02801, investigating the \\ effects of microgravity on \\ intracranial pressure. \\ Dr Williams has received \\ research support from NeuroDx \\ Development for research \\ funded by the National Institutes \\ of Health. Professor Malm \\ receives royalty payments from \\ Likvor AB, where he holds \\ patents related to the CELDA \\ infusion device, which is \\ approved within the European \\ Union, but not in the United \\ States, and receives payments \\ for a patent of a new CSF shunt \\ design created with Medtronic, \\ Inc. Professor Malm receives \\ research support as principal \\ investigator for studies from \\ the Swedish Heart-Lung \\ Foundation and the Swedish \\ National Space Board. \\ Unlabeled Use of \\ Products/Investigational \\ Use Disclosure: \\ Dr Williams and Professor \\ Malm report no disclosures. \\ C 2016 American Academy \\ of Neurology.
}




\section{CONTINUUM Normal Pressure Hydrocephalus}

\author{
KEY POINTS \\ - The only effective \\ treatment for idiopathic \\ normal pressure \\ hydrocephalus is a \\ CSF shunt. \\ Approximately 700,000 \\ persons may have \\ idiopathic normal \\ pressure hydrocephalus \\ in the United States. \\ - Idiopathic normal pressure \\ hydrocephalus should be \\ suspected for elderly \\ patients presenting with \\ unexplained, symmetric \\ gait disturbance. \\ History, clinical \\ examination, and \\ ventriculomegaly are the \\ basis for the diagnosis of \\ idiopathic normal \\ pressure hydrocephalus.
}

out of 100,000 individuals) in the age group of 70 to 79 years, and $5.9 \%$ (5900 out of 100,000 individuals) for age 80 years and older. ${ }^{2}$ In the same geographic area, the incidence of patients with iNPH who were treated with a CSF shunt was about only two to three operations per 100,000, which implies that iNPH may be underdiagnosed. ${ }^{3}$ If the prevalence of iNPH in the United States is the same, then based on US census data, ${ }^{4}$ approximately 700,000 persons may have iNPH in the United States. For comparison, the number of people in the United States with multiple sclerosis is about 400,000 , according to the National Multiple Sclerosis Society website. ${ }^{5}$ It is thus important for neurologists to know when to suspect this disorder and also how to verify and confirm the diagnosis.

This article will first focus on evaluation approaches for general neurologists and then describe methods in use at tertiary centers with expertise in complex iNPH. For a review of the pathophysiology of iNPH, see Malm and Eklund (Figure 10-1). ${ }^{6}$

\section{CLINICAL EVALUATION}

iNPH is a clinical diagnosis that is based on medical history, neurologic examination, and brain imaging with CT or MRI. The international iNPH guidelines and the Japanese iNPH guidelines both describe diagnostic criteria for $\mathrm{iNPH}^{7-9}$ The international guidelines have three different levels of diagnostic criteria: probable, possible, and unlikely. In this review, for simplicity, we have combined the definitions of probable and possible, and describe them together as iNPH.

Briefly, patients with possible or probable iNPH present with one or more of the iNPH symptoms (typically gait) with insidious onset over 3 months or more, have an MRI or CT that shows ventriculomegaly and may also show atrophy, and may have other diagnoses that contribute to the patient's symptoms, but do not explain them entirely. Patients with probable iNPH also have physiologic evidence in support of the diagnosis.

\section{Typical Presentations}

iNPH should be suspected in elderly patients presenting with unexplained, symmetric gait disturbance, which is the primary symptom of iNPH. Although dementia and incontinence are part of the so-called iNPH triad and are frequently present, the complete triad is not required to suspect the disorder.

Because the diagnosis of iNPH requires the exclusion of other diagnoses that would completely explain the patient's symptoms, an extensive and detailed history of each of the symptoms is required, which can be difficult if the patient has impaired memory. Thus, it is best to have a family member accompany the patient. With careful review, most patients will be found to have symptoms starting insidiously and progressing slowly over at least 3 to 6 months prior to presentation in clinic.

Known causes of hydrocephalus, such as intracranial hemorrhage, trauma, or infections of the central nervous system, should be sought, as patients with these risk factors may have secondary hydrocephalus. Patients who have undergone an intracranial neurosurgical procedure should be suspected of having secondary hydrocephalus.

Some patients are referred for evaluation of possible iNPH because a CT or MRI scan reveals ventriculomegaly as an incidental finding. Sometimes, the patient is asymptomatic and has no neurologic examination findings to suggest iNPH. Such patients do not meet the criteria of iNPH and do not require prognostic testing; however, they may be at risk for future development of symptoms and should be seen at intervals between 1 and 2 years for 


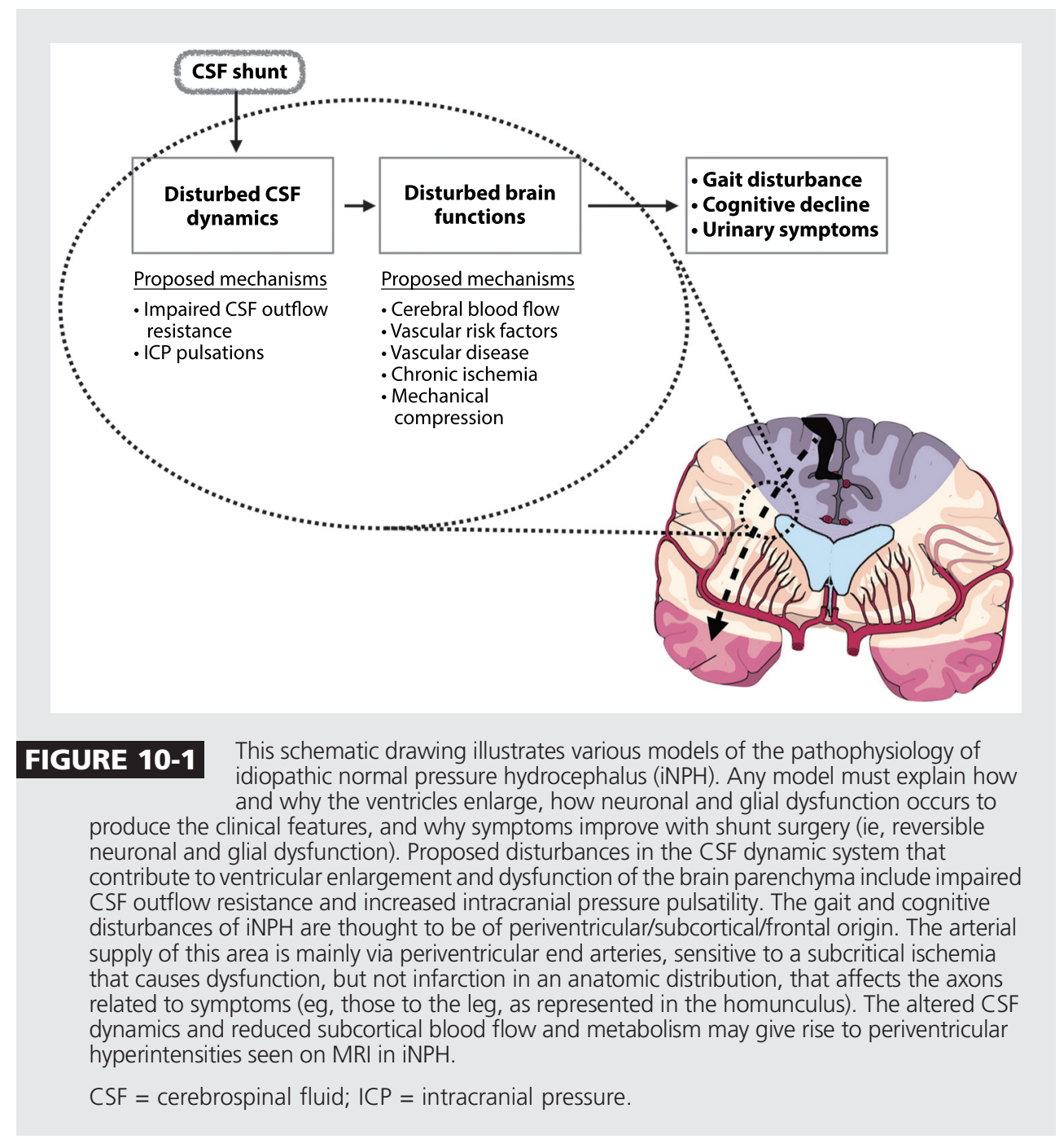

reevaluation, or patients should be advised to seek medical care if they develop any symptoms of concern.

\section{Neurologic Examination and Typical Symptoms}

Except for abnormal findings of balance, gait, and cognitive functions, the neurologic examination in patients with iNPH is normal. Symptoms of iNPH are symmetric; therefore, lateralizing findings should increase suspicion of other disorders. There should be no signs of hemiparesis or paraparesis (ie, myelopathy). Spasticity, hyperreflexia, and other upper motor neuron findings are atypical.
Gait impairment. The gait impairment in iNPH is best characterized as a higher-level gait disorder, which, in the absence of primary sensorimotor deficits, cerebellar dysfunction, or involuntary movements, involves difficulty integrating sensory information about the position of the body in its environment, including the effect of gravity and properly selecting and executing motor plans for gait or postural reflexes. ${ }^{10,11}$ The impairment should be symmetric unless coexisting musculoskeletal disorders (eg, knees, hips, spine) cause asymmetry. Findings include difficulty with transitional movements (sitting to standing or

\section{KEY POINT}

- Spasticity, hyperreflexia, and other upper motor neuron findings are atypical in patients with idiopathic normal pressure hydrocephalus. 


\section{CONTINUUM Normal Pressure Hydrocephalus}

\section{KEY POINTS \\ - The features of gait impairment in patients with idiopathic normal pressure hydrocephalus can be difficult to distinguish from those of neurodegenerative disorders with motor involvement, such as parkinsonism or dementia with Lewy bodies. \\ Neuroimaging with either CT or MRI is required for the diagnosis of idiopathic normal pressure hydrocephalus. \\ An Evans ratio of more than 0.3 indicates large ventricles, and a ratio of more than 0.33 indicates very large ventricles, but is not specific for idiopathic normal pressure hydrocephalus.}

standing to sitting); gait initiation failure; shuffling and poor foot clearance; tripping, falling, or festination; unstable multistep turns; and retropulsion or anteropulsion. ${ }^{11,12}$ The severity of gait impairment in iNPH is variable, and the features can be difficult to distinguish from neurodegenerative disorders with motor involvement, such as parkinsonism or dementia with Lewy bodies.

Cognitive impairment and dementia. Symptoms of dementia in iNPH overlap with those of other dementias, including difficulty managing finances, taking medications properly, driving, and keeping track of appointments. Some patients with iNPH present with mild cognitive impairment rather than dementia. Screening tests such as the Mini-Mental State Examination (MMSE) or Montreal Cognitive Assessment (MoCA) are advised. ${ }^{13}$ The cognitive findings of iNPH reflect involvement of the prefrontal brain structures, similar to a subcortical dementia, with executive dysfunction (eg, slow processing, difficulty with problem solving) and memory deficits with poor retrieval and relatively intact recognition memory. ${ }^{14-16}$ Impaired naming, agnosia, rapid forgetting that does not benefit from cueing, hallucinations, and failure to recognize close family or friends should raise concern for other causes of dementia. Symptoms of depression are common in iNPH, and depression screening is helpful. ${ }^{17}$ Delirium is not typical in iNPH and implies the presence of a concomitant disorder or medication side effect.

Urinary urgency and incontinence. Urgency and frequency are the most common urinary symptoms and may occur with or without incontinence. ${ }^{18}$ Patients are usually aware of the urinary urge and are concerned about their incontinence. Incontinence without awareness of urinary urge or that one's clothes are wet is not characteristic of
iNPH. Patients or family should be asked about the use of incontinence pads or undergarments, as occasionally they do not consider the patient to be incontinent if the urine is contained by the pads or undergarments. Because bladder symptoms are very common among the elderly, other causes are frequently present in patients with suspected iNPH.

\section{Imaging}

Neuroimaging with either CT or MRI is required for the diagnosis of iNPH; however, MRI is preferable. In iNPH, the lateral and third ventricles are enlarged and no obstruction to CSF flow should be present. If obstructive hydrocephalus is suspected, which occurs in a small percentage of patients, MRI should be obtained to evaluate for sites of obstruction.

A screening test for ventricular enlargement is the Evans ratio or index, which is the ratio of the widest frontal horn span to the widest diameter of the brain on the same axial image (Figure 10-2 ${ }^{19}$ ). An Evans ratio of more than 0.3 indicates large ventricles, and a ratio of more than 0.33 indicates very large ventricles, but is not specific for iNPH.

Distinguishing dilated ventricles due to cerebral atrophy from iNPH is difficult. Focal atrophy is often indicative of a degenerative dementia, particularly if it is asymmetric (eg, frontotemporal dementia) or is stereotypical, such as hippocampal atrophy in Alzheimer dementia. In iNPH, the sylvian fissures are often widened out of proportion to the cortical sulci, which are flattened ("high tight" convexity) ${ }^{20}$ (Figure 10-2), which is thought to suggest a block of CSF flow over the cerebral convexity to the arachnoid granulations. Japanese researchers have described this as disproportionately enlarged subarachnoid space hydrocephalus (DESH). 


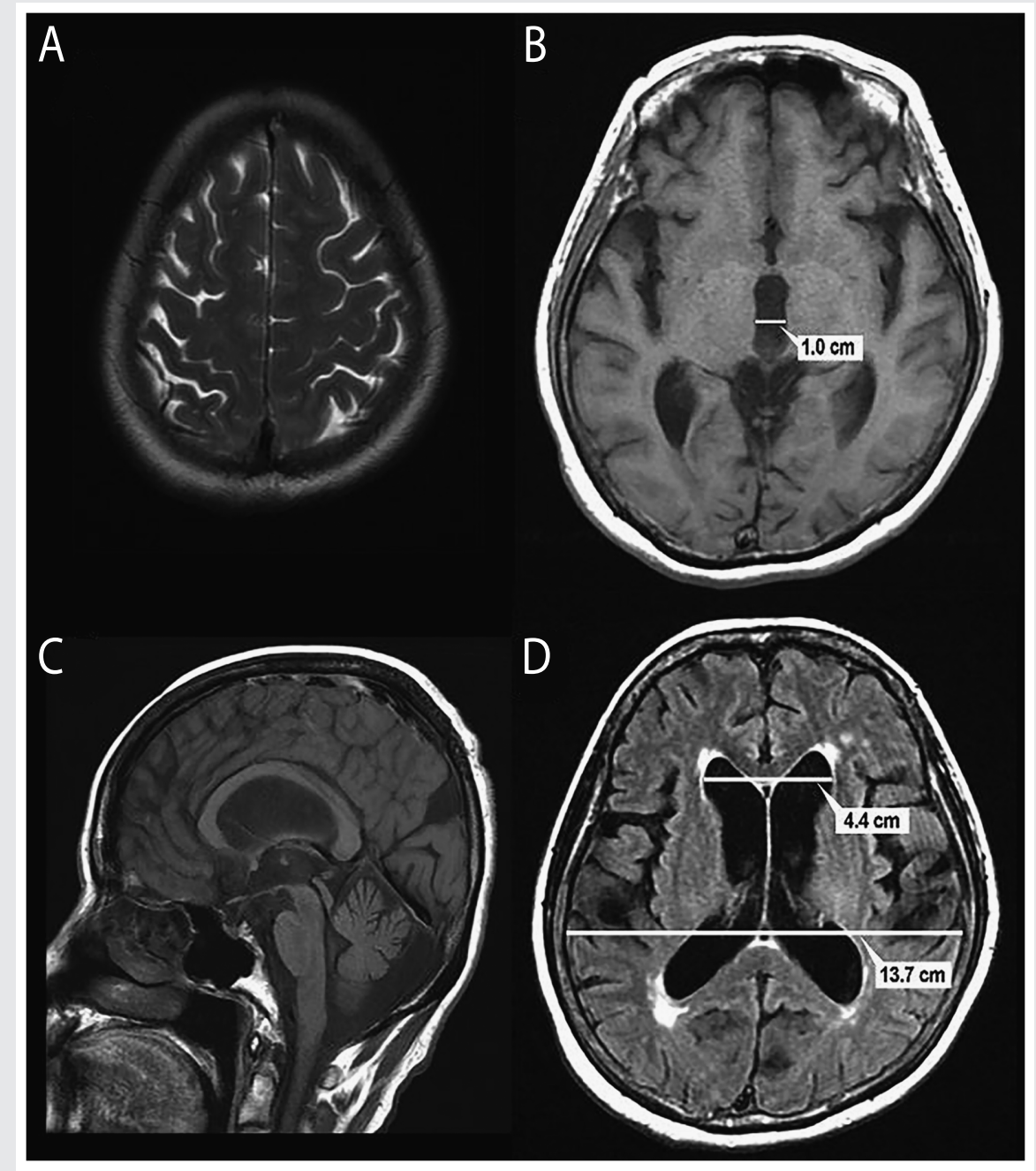

FICURE 10-2 MRI of a 73-year-old woman with impairment of gait and balance, bladder control, and cognition for 3 years. A, Axial T2 MRl consistent with the Japanese "high and tight" criteria for the convexity. The interhemispheric fissure is effaced. $B$, Axial T1 MRI shows a widened third ventricle with a span of $1.0 \mathrm{~cm}$. C, Sagittal T1 MRI shows bowing of the corpus callosum and a pulsation artifact (flow void) in the sylvian aqueduct $D$, Axial fluid-attenuated inversion recovery (FLAIR) MRI shows measurement of the Evans ratio. The diameter of the frontal horns is $4.4 \mathrm{~cm}$, the widest brain diameter is $13.7 \mathrm{~cm}$, and the Evans ratio is 0.32 .

Reprinted with permission from Williams MA, Relkin NR, Neurol Clin Pract. ${ }^{19}$ cp.neurology.org/content/3/5/ 375.full. (c) 2013 American Academy of Neurology.

The absence of DESH may be suggestive of brain atrophy, but does not exclude the possibility of iNPH., ${ }^{9,21}$

Almost all patients with iNPH have periventricular white matter lesions that are best seen in the fluid-attenuated inversion recovery (FLAIR) or T2 sequences. Periventricular white matter lesions immediately adjacent to the ventricular wall are considered to reflect fluid movement from the ventricles into the parenchyma, but white matter lesions that are more peripheral (eg, in the corona radiata) or that are diffuse and confluent are more likely to represent ischemic change. Extensive white matter lesions are not a contraindication to shunt surgery and should 


\section{CONTINUUM Normal Pressure Hydrocephalus}

\section{KEY POINTS \\ Gait impairment is typically either the first or worst symptom in patients with idiopathic normal pressure hydrocephalus. \\ - Attempts to investigate acutely hospitalized patients for idiopathic normal pressure hydrocephalus are fraught with the risk of misattribution. \\ Identification of comorbidities is an essential part of the clinical management of idiopathic normal pressure hydrocephalus. \\ The presence of comorbidities does not exclude the possibility of idiopathic normal pressure hydrocephalus; however, comorbidities do influence the prognosis after shunt surgery.}

not be used to rule out the need for prognostic testing; however, extensive ischemic white matter lesions may limit the patient's response to shunting.

The appearance of a pulsation artifact in the cerebral aqueduct, or measurements of CSF stroke volume or velocity in the aqueduct using phasecontrast methods ${ }^{22}$ cannot be used alone to recommend shunt surgery, but can support the diagnosis of iNPH and the need for further testing.

\section{DIFFERENTIAL DIAGNOSIS}

The diagnosis of iNPH is rarely an either/or situation, as it is uncommon to see "pure" iNPH. Table 10-1 ${ }^{19}$ describes common differential diagnoses that should be considered. Tests commonly ordered to evaluate the differential diagnosis include typical dementia blood work (eg, complete blood count, biochemical profile, vitamin $\mathrm{B}_{12}$, folate, thyroid-stimulating hormone [TSH], and when indicated, rapid plasma reagin [RPR], Lyme titers, and vitamin D), as well as imaging of the cervical or lumbosacral spine. Polyneuropathy, which is common in the elderly, is an important comorbidity. As a general rule, a differential diagnosis that is sufficient to explain the patient's symptoms and is treatable should be treated before any further testing or treatment of iNPH is undertaken.

Three important and common presentation variations deserve special attention for the differential diagnosis. First, patients with ventriculomegaly who have only cognitive impairment or only incontinence should be evaluated for other disorders before considering iNPH. Most published research and guidelines indicate that nearly all patients have gait impairment, which is typically either the first or worst symptom.

Second, patients with gait impairment and urinary symptoms but no cognitive impairment should be con- sidered for spinal cord disorders before evaluating for iNPH.

Third, patients who have been admitted to the hospital for delirium or failure to thrive and are incidentally found to have ventriculomegaly on neuroimaging should not be investigated for iNPH until the underlying cause of the delirium has been found, treatment has been initiated, and the patient has been discharged from the hospital and had time to return to a stable baseline. Attempts to investigate acutely hospitalized patients for iNPH are fraught with the risk of misattribution, as an apparent response to CSF removal could be due to recovery from the underlying illness, or an apparent lack of response to CSF removal could be due to persistence of the underlying illness.

\section{ROLE OF COMORBIDITIES}

iNPH affects the elderly, many of whom have other conditions (ie, comorbidities that contribute to their symptoms). ${ }^{23}$ However, if the comorbidities are not sufficient to explain the patient's symptoms, then iNPH should be investigated. The presence of comorbidities does not exclude the possibility of iNPH; however, comorbidities do influence the prognosis after shunt surgery. The specific symptoms that will improve and the extent of clinical improvement that can be expected after treatment of iNPH will depend on the proportional contribution of the iNPH and the comorbidities to the patient's clinical presentation. For instance, a patient with possible Alzheimer disease dementia, along with the iNPH, is likely to have a worse cognitive response to shunting than a patient with pure iNPH. Thus, an important part of the iNPH investigation is to identify and treat any treatable comorbidities and discuss their potential influence on surgical outcome with the patient and family. If there is any doubt as to 


\section{TABLE 10-1 Differential Diagnosis of Idiopathic Normal Pressure Hydrocephalus $^{\mathrm{a}}$}

\section{Gait Dementia Incontinence}

Disorders that may have all three symptoms

Idiopathic normal pressure hydrocephalus (iNPH) with or without comorbidities

Parkinsonism

Dementia with Lewy bodies

Corticobasal degeneration

Progressive supranuclear palsy

Multiple system atrophy

Vascular dementia

Neurosyphilis

Medication side effects

Multifactorial - any combination of diagnoses with or without iNPH

X $x$

$x \quad x$

$x \quad x$

$x \quad x$

$x \quad x$

$x \quad x$

$x \quad x$

$x \quad x$

$x \quad x$

$x \quad x$

$X$

$x$

$\mathrm{X}$

$\mathrm{X}$

$\mathrm{X}$

$\mathrm{X}$

$\mathrm{X}$

$\mathrm{X}$

$\mathrm{X}$

$\mathrm{X}$

\section{Disorders that may have two symptoms}

Multifactorial - any combination of diagnoses with or without iNPH

iNPH with or without comorbidities

Vitamin $\mathrm{B}_{12}$ deficiency

Cervical stenosis and myelopathy

Lumbosacral stenosis

Peripheral neuropathy

$\begin{array}{lll}X & X & X \\ X & X & \\ X & x & \\ X & & X \\ X & & X \\ X & & \end{array}$

Disorders that may have only one symptom

iNPH

$x$

Degenerative arthritis of the hips, knees, ankles

Spinocerebellar degeneration

$\mathrm{x}$

$\mathrm{X}$

Peripheral vascular disease (claudication)

$\mathrm{x}$

Alzheimer dementia

Frontotemporal dementia

Depression

Hypothyroidism

Sleep apnea

Prostatic hypertrophy/obstructive uropathy

Pelvic floor abnormalities

Interstitial cystitis

X

$\mathrm{X}$

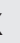 \\ $x$}

$x$

$x$

\section{X}

$\mathrm{X}$

$\mathrm{X}$

$\mathrm{X}$

0
0
$x$
$x$




\section{CONTINUUM Normal Pressure Hydrocephalus}

\section{KEY POINT}

- The international and Japanese guidelines support shunt surgery as effective treatment of idiopathic normal pressure hydrocephalus, as does the American Academy of Neurology practice guideline.

TABLE 10-1 Differential Diagnosis of Idiopathic Normal Pressure
Hydrocephalus ${ }^{\mathbf{a}}$ Continued from page 585

\begin{tabular}{lcr} 
& Gait & Dementia \\
\hline $\begin{array}{l}\text { Disorders that can aggravate other } \\
\text { symptoms }\end{array}$ & & \\
Visual impairment & $\mathrm{X}$ & $\mathrm{X}$ \\
Hearing impairment & $\mathrm{X}$ & \\
Obesity & $\mathrm{X}$ & \\
Cardiovascular disease & $\mathrm{X}$ & \\
Pulmonary disease & $\mathrm{X}$ & \\
Chronic lower back pain & $\mathrm{X}$ & \\
Vestibular disorders &
\end{tabular}

$\bar{a}$ Reprinted with permission from Williams MA, Relkin NR, Neurol Clin Pract. ${ }^{19}$ cp.neurology.org/ content/3/5/375.full. () 2013 American Academy of Neurology.

whether comorbidities completely explain the patient's symptoms, then testing for iNPH should be performed.

\section{INDICATIONS FOR SHUNT SURGERY}

The clinical presentation of iNPH by itself is usually not sufficient to recommend shunt surgery, as each of the primary iNPH symptoms has multiple potential etiologies, and enlarged ventricles can be seen either with hydrocephalus or with brain atrophy. Predictive tests to determine the likelihood of shunt responsiveness are recommended. The CSF tap test is a predictive test that easily can be performed at most neurologic centers. If multiple comorbidities or differential diagnoses make the diagnosis uncertain, referral to specialized centers that can perform ancillary tests (see the following section on specialized diagnostic testing) can help to select patients with a high likelihood of responding to shunt surgery.

The international and Japanese guidelines support shunt surgery as effective treatment of iNPH, as does the American Academy of Neurology (AAN) practice guideline. ${ }^{7-9,24}$ Endo- scopic third ventriculostomy is not effective in treatment of iNPH. ${ }^{25,26}$ As of 2016, no medical treatments are effective in iNPH, and, specifically, no evidence supports the use of acetazolamide ${ }^{27}$ although this medication is occasionally prescribed and has been evaluated in a small pilot study. ${ }^{28}$

\section{Specialized Diagnostic Testing}

The international guidelines recommend tests of CSF hydrodynamics (tap test, external lumbar drainage, and infusion testing) to demonstrate either that the patient has the potential to respond to shunt surgery or that the patient has abnormal CSF hydrodynamics that are consistent with hydrocephalus..$^{7-9,24,29}$ The tap test, also known as the large-volume lumbar puncture (LP), will be described here. Infusion testing and external lumbar drainage will be described in the following section on tertiary centers with expertise in complex iNPH.

Tap test. The rationale for testing a patient's response to CSF removal is that doing so temporarily creates the physiologic effect of a shunt for the patient. The hypothesis is that if the patient 
has iNPH, a significant response to CSF removal should be seen, and shunt surgery should help.

Properly performing the tap test rests on two principles. ${ }^{19}$ First, the patient must be examined before and after the LP so that the response to CSF removal can be documented and quantified. Impaired gait is the symptom most likely to respond, and use of a standardized evaluation of gait, with or without video recording or computer-assisted assessment, is helpful. The baseline assessment should be done immediately before the LP. The authors specifically recommend that a health care professional with the appropriate skills (eg, neurologist, nurse, or physical therapist) assess and document the patient's gait before and after the LP, as relying only on the report of the patient or family is liable to be influenced by their desire to see improvement.

Second, the volume of CSF removed must be large enough to improve the patient's CSF hydrodynamics enough for the brain to respond and the symptoms to improve. The LP should be done with an 18- or 20-gauge spinal needle. Typical tap test protocols remove $30 \mathrm{~mL}$ to $50 \mathrm{~mL}$ of CSF. The interval between the LP and the formal follow-up examination is usually between 2 and 4 hours. The patient does not have to stay supine after the LP, and our experience is that headache and nausea after LP are uncommon in the iNPH population. We have patients lie down only if they develop adverse events and encourage them and their families to be active (eg, going for a snack or taking a walk) after the LP, which enables them to determine in realistic circumstances whether the patient's gait has improved.

The same formal gait assessments should be performed before and after the LP. If the response is significant, shunt surgery can be recommended. ${ }^{30}$ However, the absence of response to
CSF removal does not exclude shunt responsiveness because the tap test is specific (range of $60 \%$ to $100 \%$ in various studies), rather than sensitive (range of 50\% to 80\%). External lumbar drainage can be considered if iNPH is still clinically suspected after a patient has failed to improve after the tap test.

\section{SHUNT BASICS}

The purpose of a shunt is to divert CSF from the craniospinal CSF space to another anatomic space where the CSF can be reabsorbed. The most common configuration is a VP shunt. A VP shunt consists of three parts (Figure 10-3): a proximal catheter, usually inserted in the right lateral ventricle; a distal catheter with its tip in the peritoneal cavity; and a shunt valve between the proximal and distal catheters. The valve consists of a mechanism that opens when the pressure difference across the valve (ie, between the ventricle and peritoneal cavity) exceeds the pressure required to open the valve. Once the valve opens, CSF flows through the tubing. An alternate configuration is a lumboperitoneal shunt, in which the proximal catheter is placed in the lumbar CSF space.

Two types of shunt valves are widely used: shunts with a fixed-valve opening pressure and programmable shunts with variable valve opening pressure that can be changed via an external magnetic programming device. Several different makes and models of adjustable shunts are available, and the devices for adjusting them are not interchangeable. Flow through shunt valves is unidirectional, preventing reflux into the ventricles. Some shunts also have an antisiphon device that has a higher resistance in the vertical position to prevent overdrainage of CSF when patients are upright that can cause low-pressure symptoms or, in severe circumstances, subdural fluid collections or hematomas.

\section{KEY POINTS}

If a patient has idiopathic normal pressure

hydrocephalus, a significant response to CSF removal should be seen and shunt surgery should help.

A ventriculoperitoneal shunt consists of three parts: a proximal catheter, usually inserted in the right lateral ventricle; a distal catheter with its tip in the peritoneal cavity; and a shunt valve between the proximal and distal catheters.

Several different makes and models of adjustable shunts are available, and the devices for adjusting them are not interchangeable. 


\section{CONTINUUM Normal Pressure Hydrocephalus}

\section{KEY POINT}

Some, but not all, adjustable shunts are susceptible to strong external magnetic fields

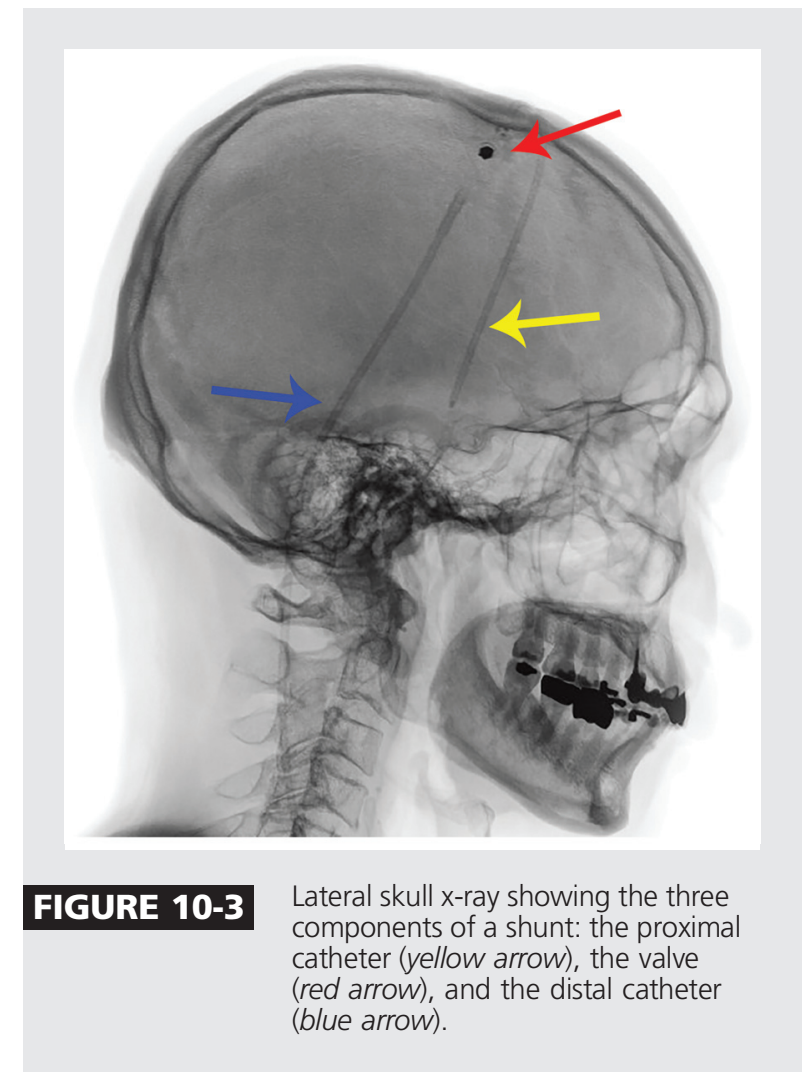

Depending on the design of the valve mechanism, some, but not all, adjustable shunts are susceptible to strong external magnetic fields (eg, MRI) or to weak external magnetic fields (eg, household magnets or magnets from toys) that are brought within 1 to $2 \mathrm{~mm}$ of the shunt valve mechanism, which can change the shunt setting. ${ }^{31-33}$ A website for determining the safety of shunts, as well as other devices, in MRI scanners is available at $w w w$. mrisafety.com. ${ }^{34}$ Patients who have MRI-susceptible shunts are not prohibited from undergoing MRI scans; however, they should be seen soon after the MRI to have the shunt setting checked and reset if necessary. Failure to do so could result in either overdrainage if the shunt setting after the MRI is too low, or in inadequate drainage and worsening of the iNPH symptoms if the shunt setting after the MRI is too high.

The choice of shunt valve and configuration depends on the neurosur- geon's recommendation and the patient's preference. No evidence supports the use of one specific make or model of shunt over another ${ }^{29,35}$; however most tertiary centers with expertise in complex iNPH make use of shunts with adjustable settings. When patients with iNPH are selected for shunt surgery on the basis of testing described in the international and Japanese guidelines, the risk of shunt surgery is low in the context of the expected benefits, and most patients will proceed with shunt surgery.

The goal of using a shunt to treat iNPH is to improve the patient's symptoms and avoid serious complications, such as subdural effusion or hematoma. Adjustable valves offer the advantage of being able to lower the pressure setting incrementally until symptoms improve and to raise the pressure setting if low-pressure symptoms or complications emerge. The introduction of adjustable valves has dramatically lowered the need 
for shunt revisions, and most complications can be handled by changing the shunt setting. Severe complications, such as subdural hematoma with mass effect, shunt infection, and shunt obstruction, typically require neurosurgical intervention. Adjustable shunts can be used to safely manage patients with iNPH who need chronic anticoagulation. ${ }^{36}$

\section{LONGITUDINAL FOLLOW-UP AFTER SHUNT SURGERY}

Patients who have had shunt surgery should have periodic follow-up visits. Many neurosurgeons will see these patients only for a postoperative wound check and will not see them again unless they have a shunt complication that requires surgery. Although most neurologists have not been trained to provide longitudinal care of patients with iNPH after shunt surgery, they can learn to do so.

The follow-up of patients with a shunt is similar to the follow-up of patients with parkinsonism or other chronic neurologic disorders. The interval history should cover all three iNPH symptoms of gait impairment, incontinence, and dementia. The neurologic examination should include cognitive screening (eg, MMSE or MoCA), gait evaluation, and a general neurologic examination.

All symptoms in iNPH can improve after shunt surgery. The cognitive improvement is not widely appreciated, but has been confirmed in multiple studies and is more robust than the improvement seen with pharmacologic treatment of degenerative dementias. ${ }^{14-16}$

Periodic brain imaging is recommended to look for signs of overdrainage, such as subdural effusion or hematoma, particularly in the first 6 to 12 months after shunt surgery until it is determined that the patient's condition and the appearance of the scan are stable. In most instances, a CT scan without contrast suffices.
Overdrainage can be caused by a shunt setting that is too low (if using an adjustable shunt) or by a fixed valve with a setting that is too low. The main symptom of overdrainage is headache that worsens with sitting and standing and improves when lying down. Patients may also report altered hearing, typically muffled. ${ }^{37}$ A subdural effusion (hygroma) or hematoma can be seen on CT or MRI. Symptomatic patients may benefit from raising the shunt setting (Figure 10-4). Thin subdural effusions ( $2 \mathrm{~mm}$ to $5 \mathrm{~mm}$ ) in asymptomatic patients are usually not an indication for raising the shunt setting.

The setting of adjustable shunts should be confirmed during the follow-up visit, provided the neurologist has the device appropriate for the patient's shunt. Depending on the degree of symptomatic recovery and the presence or absence of low-pressure signs and symptoms, the shunt setting can be raised or lowered in small increments or left unchanged. If the setting is changed (Current Procedural Terminology code 62252, reprogramming of programmable cerebrospinal shunt ${ }^{38}$ ) then follow-up in 2 to 3 months to assess the response to the change is indicated. Once patients have reached a stable degree of recovery without low-pressure symptoms, the interval between visits can be extended to 6 to 12 months.

Symptoms of shunt malfunction should be explored, such as pain or discomfort from the shunt components, including abdominal pain. The examination includes inspection and palpation of the shunt, as rarely poor wound healing or dehiscence will be present, which requires immediate admission to the hospital and neurosurgical consultation for possible shunt surgery because of the risk of shunt infection.

Because shunt obstruction occurs in $30 \%$ or more of patients with iNPH,

\section{KEY POINTS}

- Patients who have had shunt surgery should have periodic follow-up visits.

Although most neurologists have not been trained to provide longitudinal care of patients with idiopathic normal pressure hydrocephalus after shunt surgery, they can learn to do so.

All symptoms in patients with idiopathic normal pressure hydrocephalus can improve after shunt surgery. 


\section{CONTINUUM Normal Pressure Hydrocephalus}

\section{KEY POINT}

- When patients who have been treated with shunts have worsening symptoms, physicians frequently presume that the shunt is obstructed, which is often incorrect.
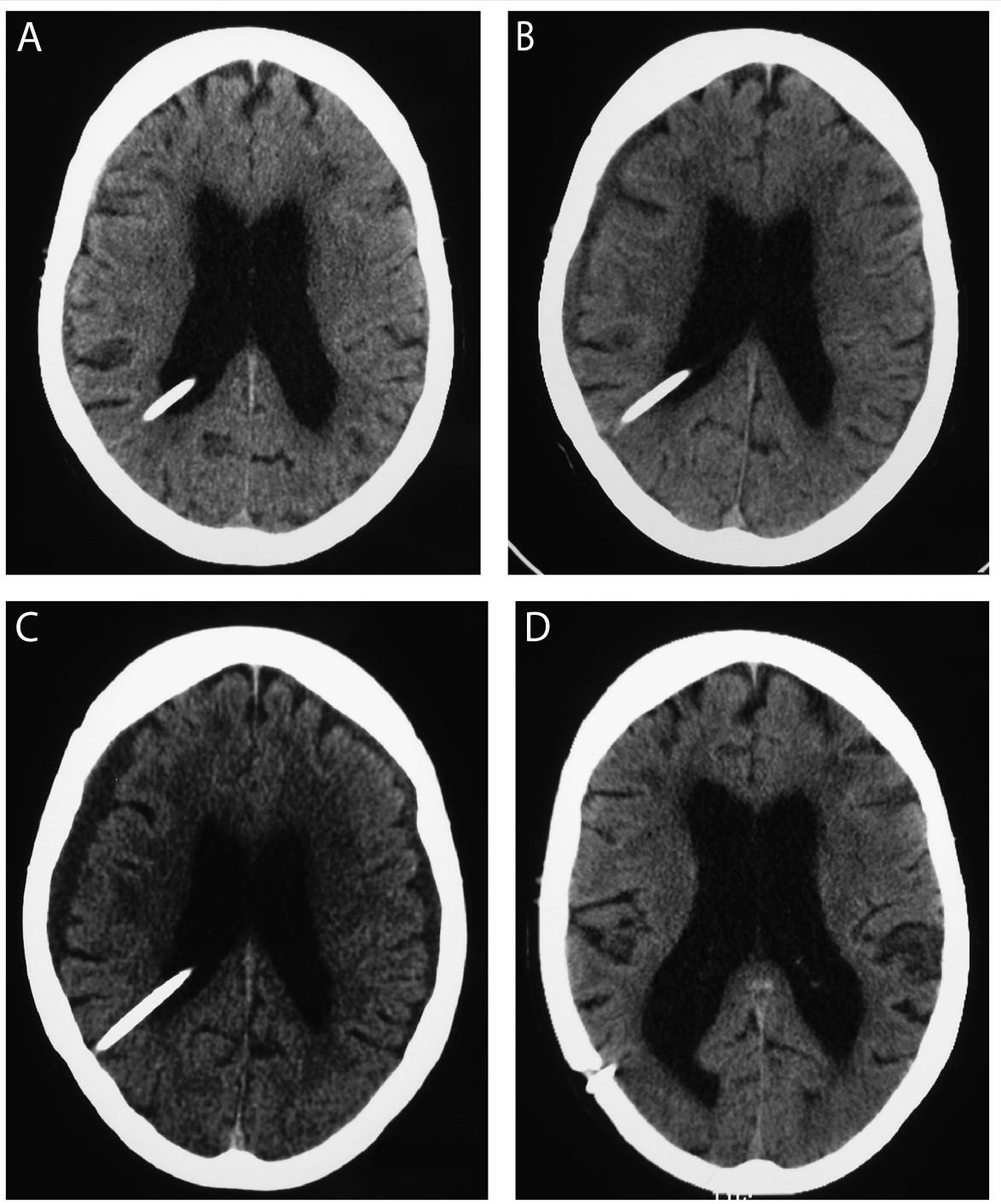

FIGURE 10-4

Serial axial CT scans without contrast over a 6-week period showing the evolution of enlarging bilateral subdural fluid collections ( $A$, from January $3 ; B$ from January $7 ; C$, from January 12) and resolution of the subdural fluid collections after the adjustable shunt was placed at the highest setting ( $D$, from February 16).

shunt obstruction symptoms should be reviewed during clinic visits. It is not possible to predict who will experience shunt obstruction or when. The return of iNPH symptoms is typically gradual, and it may be several weeks or months before patients realize that they are getting worse. Shunt obstruction in iNPH is rarely an emergency. If shunt obstruction is detected and treated, approximately $75 \%$ of patients will once again improve. ${ }^{39}$
When patients who have been treated with a shunt have worsening symptoms, physicians frequently presume that the shunt is obstructed, which is often incorrect because elderly patients may worsen for other reasons, including worsening of comorbidities or emergence of new diagnoses or conditions. Typical clinical scenarios that are of concern to patients are lagging symptom recovery, transient worsening, and insidious worsening. ${ }^{19}$ 
Some patients have recovery of only one or two symptoms after shunt surgery, while other symptoms lag behind. In most circumstances, another disorder is responsible for the lagging symptom and should be investigated further. For example, a patient whose urinary symptoms do not improve after shunt surgery may need to be referred to a urologist.

Some patients, after initial improvement, will have transient worsening of iNPH symptoms in association with another illness (eg, urinary tract infection) or with hospitalization or surgery. This pattern is similar to the worsening of latent symptoms seen in many neurologic disorders when patients experience other illnesses. After the underlying illness is identified and treated, the iNPH symptoms should improve with time.

Gradual worsening of symptoms over weeks or months may indicate shunt malfunction or the emergence of a comorbidity. In this circumstance, shunt malfunction should be investigated. Disconnection of the shunt components is easily detected by plain $\mathrm{x}$-rays, although uncommon in the iNPH population. Palpating and depressing the shunt reservoir to check for refilling is not helpful in distal shunt obstruction. A shunt patency study should be performed, which is discussed in the following section.

\section{TESTS AND SERVICES AVAILABLE AT TERTIARY CENTERS}

High-complexity patients (Table 10-2) may be better served by referral to tertiary centers with experience in diagnosis and management of complex adult hydrocephalus that utilize a multidisciplinary team of specialists, including neurologists, neurosurgeons, radiologists, and neuropsychologists, and provide a highly organized and protocolized approach to the evaluation and treatment of iNPH and related disorders.
These centers typically have access to diagnostic tests that are not available in general use, including external lumbar drainage, lumbar CSF infusion testing, tests to evaluate shunt patency, and specialized imaging approaches.

\section{Patient Flow at a Hydrocephalus Unit}

Figure 10-5 illustrates the patient flow at a tertiary clinic investigating patients for suspected iNPH. After investigation, about $60 \%$ of referred patients had a diagnosis of probable or possible iNPH. A small portion had ventriculomegaly without iNPH symptoms, or had iNPH symptoms but a normal radiologic examination. In about $10 \%$ of patients, secondary causes of hydrocephalus were found. About one-fourth had an alternate diagnosis, such as parkinsonism, Alzheimer dementia, or vascular dementia.

\section{CSF Infusion Testing}

Infusion testing for assessment of CSF hydrodynamics is commonly used in Europe to diagnose iNPH, but is rarely used in the United States or Canada. The CSF infusion test involves infusing Ringer lactate via one spinal needle while simultaneously recording CSF pressure via a second spinal needle. ${ }^{40,41}$ Several variables, such as intracranial pressure (ICP), outflow resistance $\left(\mathrm{R}_{\text {out }}\right)$, CSF formation rate, pulse pressure curve, ${ }^{42}$ and dural venous pressure can be measured or indirectly calculated. $\mathrm{R}_{\mathrm{Out}}$, or its inverse, CSF conductance, is a measure of the resistance to CSF resorption in the central nervous system. One of the most consistent findings in iNPH research is that patients have an increased resistance to CSF outflow ( $\mathrm{R}_{\text {out }}$ ). ${ }^{43}$ Several methods for infusion testing exist, and the value and accuracy of $R_{\text {out }}$ are method dependent. ${ }^{40}$ Reference values for healthy elderly exist. ${ }^{41}$ Infusion

\section{KEY POINTS}

Three typical clinical scenarios of worsening symptoms are lagging symptom recovery, transient worsening, and insidious worsening.

High-complexity patients with idiopathic normal pressure hydrocephalus may be better served by referral to tertiary centers with expertise in complex idiopathic normal pressure hydrocephalus.

Supplementary tests can be used to include patients for surgery, but not to exclude them.

- Infusion testing for assessment of CSF hydrodynamics is commonly used in Europe.

An increased resistance to CSF outflow ( $R_{\text {out }}$ ) is one of the most consistent findings in idiopathic normal pressure hydrocephalus research 


\section{CONTINUUM Normal Pressure Hydrocephalus}

\section{TABLE 10-2 High-Complexity Patients With Adult Hydrocephalus}

- Patients with severe ventriculomegaly

- Patients who first received a shunt or endoscopic third ventriculostomy in childhood or as young adults

- Patients who have congenital or childhood-acquired hydrocephalus but were not treated

- Patients who require chronic anticoagulation

- Patients with severe neurologic impairment

- Patients with atypical presentations (eg, no gait impairment)

- Patients who need shunt adjustments

- Patients with shunt complications, including wound dehiscence or suspected shunt infection, subdural hematoma in need of surgical evacuation, or intraperitoneal complications

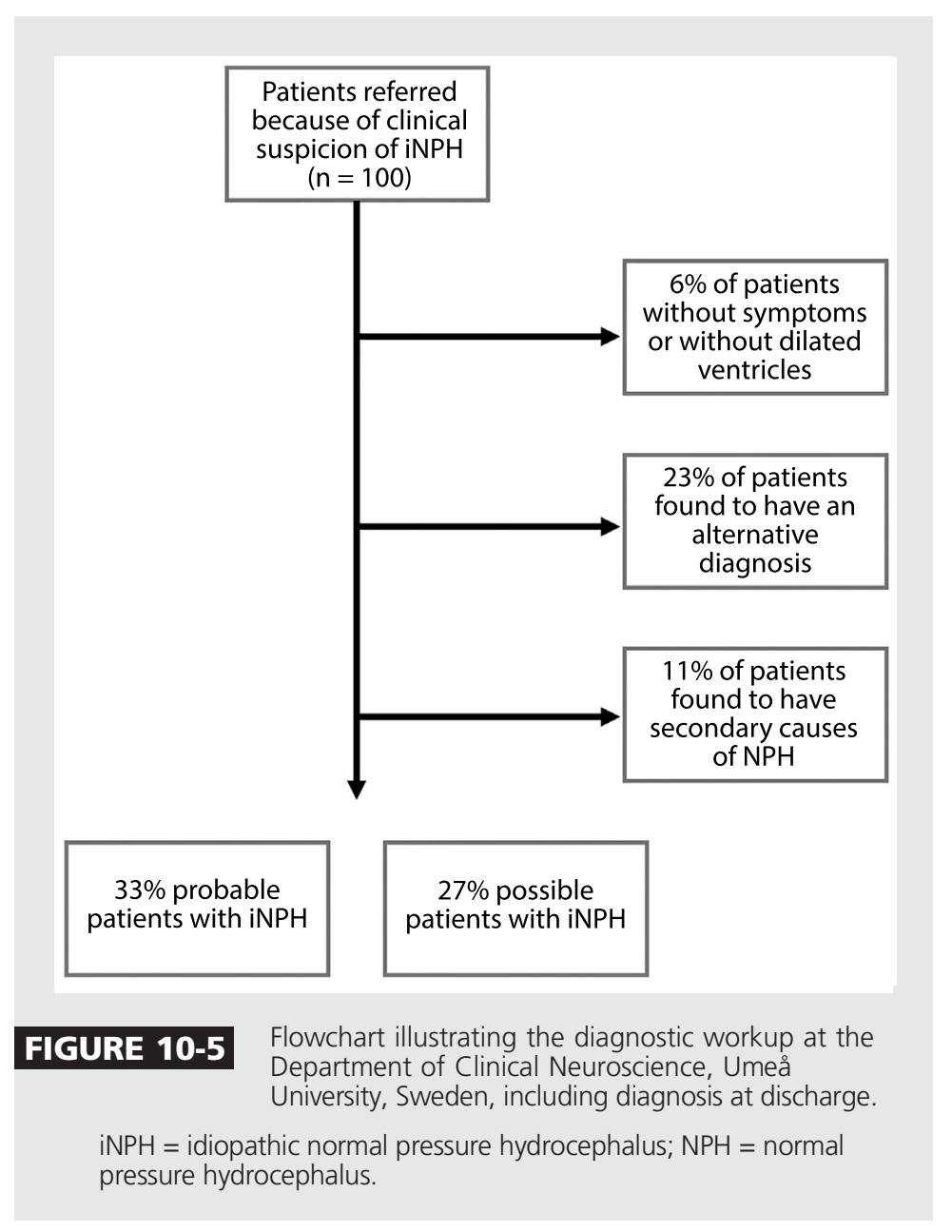


testing requires specialized equipment, which is commercially available in Europe and other parts of the world, ${ }^{44}$ but not the United States, and requires considerable expertise on the part of the physicians who perform it.

\section{External Lumbar Drainage}

External lumbar drainage involves continuous CSF drainage and requires hospitalization. A spinal catheter is inserted via a Tuohy needle (Figure 10-6) and connected to a sterile, closed system for controlled CSF drainage at approximately $10 \mathrm{~mL} / \mathrm{h}$ (Case 10-1). ${ }^{45}$ The patient's gait should be examined before the procedure, daily during CSF drainage, and after removal of the catheter. Neuropsychological testing before and after external lumbar drainage may also be helpful. Most publications have cited 72 hours of CSF drainage, although some centers drain CSF for shorter periods. External lumbar drainage is said to be accurate, with both a high positive- predictive value and a high negativepredictive value. The most frequent serious complication of external lumbar drainage is bacterial meningitis, seen in $2 \%$ to $3 \%$ of patients. ${ }^{48,49}$ Because of the potential risks and the need for specialized inpatient nursing, external lumbar drainage should be performed only by centers that have an organized team and approach. Attempts at ad hoc performance of external lumbar drainage are discouraged.

\section{Intracranial Pressure Monitoring}

Recording of ICP has been used as a diagnostic test for iNPH for 40 years. ${ }^{50}$ The recordings in iNPH reveal waveform abnormalities similar to those originally described for brain tumor or acute injury, ie, so-called B waves and A waves, particularly in sleep. The presence of unstable ICP (predominantly B waves) in NPH is well known, and the correlation with iNPH shunt responsiveness varies from $50 \%$ to $90 \% .{ }^{51-53}$ Most ICP monitoring has

\section{KEY POINTS}

- Attempts at ad hoc performance of external lumbar drainage in patients with idiopathic normal pressure hydrocephalus are discouraged.

- The presence of unstable intracranial pressure (predominantly B waves) in idiopathic normal pressure hydrocephalus is well known.

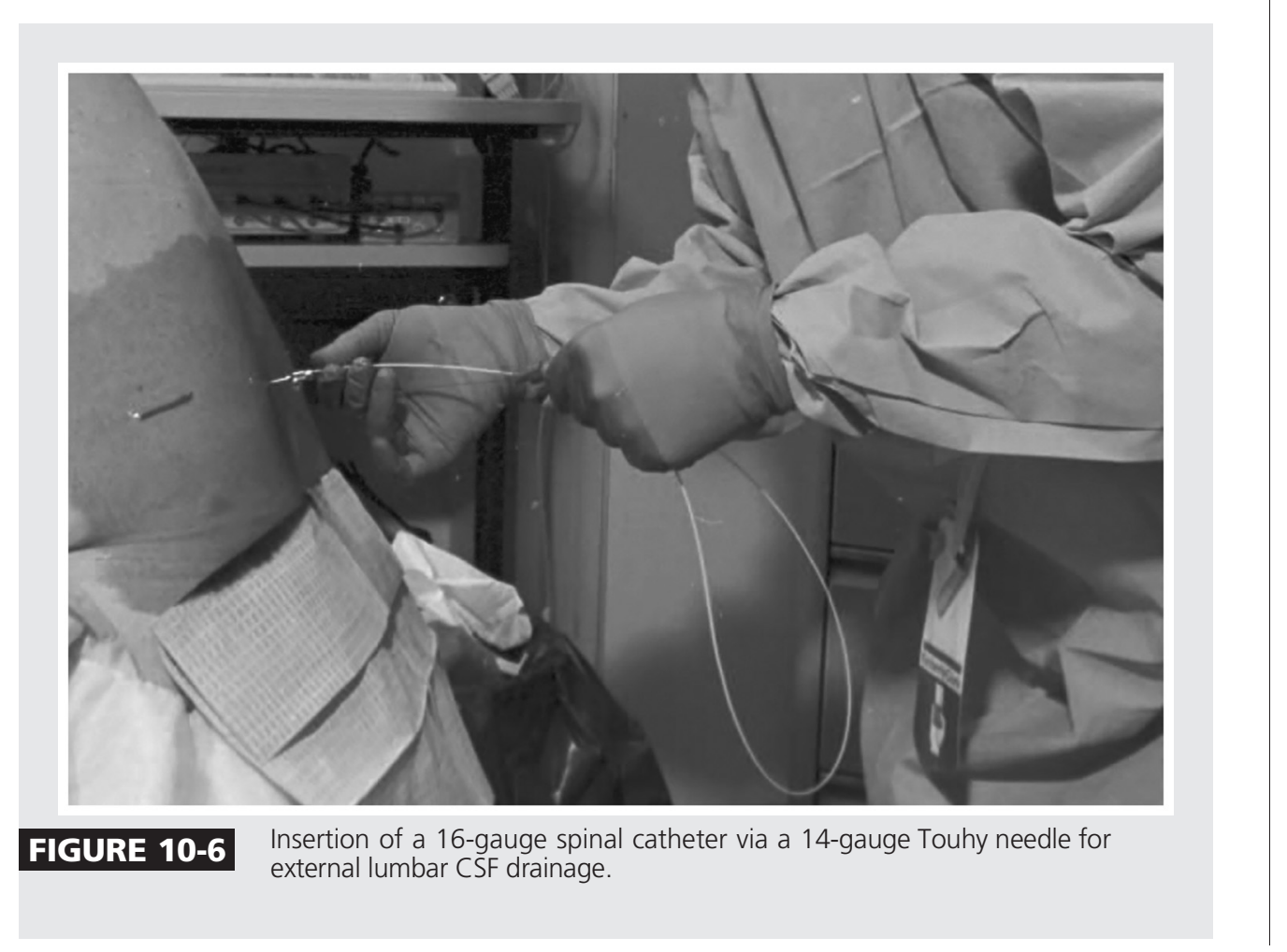




\section{CONTINUUM Normal Pressure Hydrocephalus}

\section{Case 10-1}

An 82-year-old woman was referred for difficulty with gait, balance, bladder control, and cognition. She had experienced gait trouble for "many years," but it had been much worse over the past year. She had problems getting in and out of seats, initiating gait, and turning, and she had festination. She used a walker with wheels. Urinary symptoms included urgency, but sometimes her urine would not flow when she was on the toilet, and she lost urine with coughing or straining. Cognitively, she had trouble finding words, but managed her money, medications, and appointments, which her daughter confirmed. Her medications included alprazolam, oxycodone, and tramadol. She was unable to live independently.

The Montreal Cognitive Assessment (MoCA) score was 14 out of 30 , and the Tinetti scale score ${ }^{46}$ (a standardized gait and balance assessment) was variable from 12 out of 28 to 16 out of 28 . Motor examination revealed paratonia versus rigidity. Brain MRI scan (Figure 10-7) showed an Evans ratio of 0.40 , bilateral frontal atrophy, and possible disproportionately enlarged subarachnoid space hydrocephalus (DESH).

She did not improve after cessation of alprazolam, oxycodone, and tramadol, and thus was admitted to the hospital for external lumbar drainage. Over 3 days, $690 \mathrm{~mL}$ CSF was drained. The Tinetti scale score improved from 5 to 10 out of 28 on admission to 21 to 25 out of 28 after external lumbar drainage. The Timed Up and Go Test (TUG), ${ }^{47}$ a standardized assessment in which a patient is observed and timed while arising from an arm chair, walking 3 meters, turning around, walking back, and sitting down again, improved from 36.65 seconds to 16.25 seconds after external lumbar drainage. She was referred to a neurosurgeon. A programmable ventriculoperitoneal shunt was inserted at a setting with an opening pressure of approximately $115 \mathrm{~mm} \mathrm{H}_{2} \mathrm{O}$.
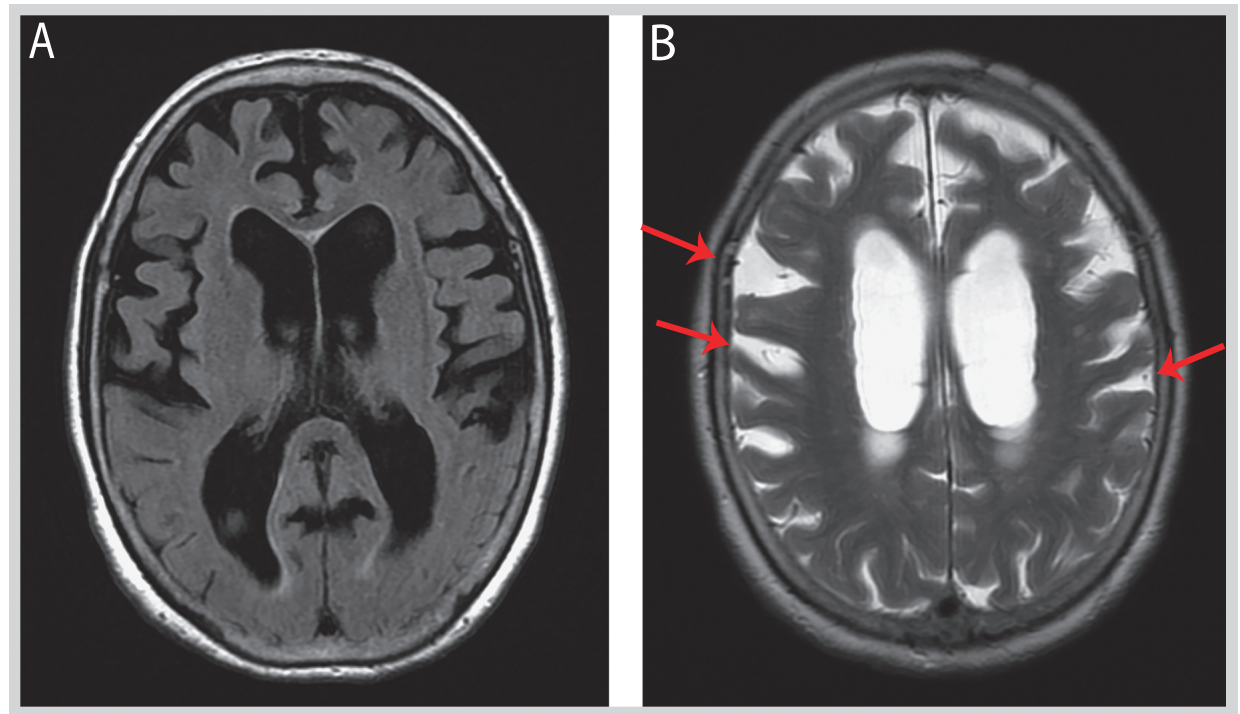

FIGURE 10-7 Imaging from the patient in Case 10-1. The Evans ratio is 0.40 . The widening of the sulci in the frontal lobes $(A, B)$ suggests atrophy; however, the pattern also raises the possibility of disproportionately enlarged subarachnoid space hydrocephalus (DESH), particularly the widening of the sulci higher over the convexities (B, arrows)

Three months after shunt surgery, she no longer needed a walker and only occasionally used a cane. The MoCA score was 20 out of 30 and the Tinetti scale score was 25 out of 28 , which was normal. Because she was still improving, the shunt setting was not changed. 
Continued from page 594

Nine months after shunt surgery, she was living in her own home part time and able to do light housework and manage all of her affairs. The MoCA score was 24 out of 30 and the Tinetti scale score was 22 out of 28 .

Fourteen months after shunt surgery, she had passed a formal driving evaluation. She was living independently. Her gait examination was described as cautious, but with no shuffling. Because her condition was stable, she was seen annually for follow-up.

Comment. This case illustrates the evaluation and management of a patient with possible idiopathic normal pressure hydrocephalus from the beginning to a sustained successful outcome after shunt surgery.

been done with ventricular catheters or other intracranial devices. ${ }^{50,53}$ Elderly patients with obstructive hydrocephalus may present with symptoms of iNPH. In such cases, diagnostic ICP monitoring via intracranial methods should be considered. Because most patients with iNPH have communicating hydrocephalus, ICP monitoring can be performed safely via lumbar catheter, and the authors tend to reserve ICP monitoring for patients whose gait impairment is so mild that it may be difficult to ascertain improvement with CSF drainage alone. ${ }^{45}$ Recently, analysis of the amplitudes of the ICP pulse pressure has been proposed as a predictive test in iNPH. High pulse pressure amplitudes are

\section{Case 10-2}

A 77-year-old man was referred for evaluation of possible idiopathic normal pressure hydrocephalus (iNPH) at a center that uses CSF infusion testing. The investigation revealed a low CSF outflow conductance $\left(6.2 \mathrm{~mm}^{3} / \mathrm{s} / \mathrm{kPa}\right)$, which is a typical finding in iNPH. (Normal values are above $10 \mathrm{~mm}^{3} / \mathrm{s} / \mathrm{kPa}$.) A shunt with a fixed opening pressure and an antisiphon device was inserted.

At 3 and 12 months after surgery, he had a marked clinical improvement. The conductance was increased, as expected $\left(57 \mathrm{~mm}^{3} / \mathrm{s} / \mathrm{kPa}\right.$ and $59 \mathrm{~mm}^{3} / \mathrm{s} / \mathrm{kPa}$, respectively), because the shunt, which is an alternate CSF outflow channel, increases the measured conductance.

The patient's gait and cognitive function deteriorated 36 months after the shunt surgery. The conductance was reevaluated and was lower than before $\left(25 \mathrm{~mm}^{3} / \mathrm{s} / \mathrm{kPa}\right)$, but still higher than the preoperative value. After consideration, the original shunt valve was replaced with an adjustable valve set at $120 \mathrm{~mm} \mathrm{H}_{2} \mathrm{O}$. However, the patient did not improve as expected.

Another CSF dynamic investigation was performed, showing CSF outflow conductance results $\left(7.7 \mathrm{~mm}^{3} / \mathrm{s} / \mathrm{kPa}\right)$ that were the same as the preoperative value, indicating that the shunt system was obstructed. The shunt was revised again, after which the patient improved.

The patient's iNPH symptoms once again worsened 57 months after the original shunt surgery. Another CSF dynamic investigation revealed a high conductance $\left(33 \mathrm{~mm}^{3} / \mathrm{s} / \mathrm{kPa}\right)$, consistent with a functioning shunt. The shunt setting was lowered, but the patient did not improve, and the cause of his worsening was attributed to his comorbidities.

Comment. This case illustrates how an infusion technique can be used for patient selection, but also to assess postoperative shunt function.

Case modified with permission from Eklund A, et al, Med Biol Eng Comput. ${ }^{50}$ (c) 2004 Springer International Publishing AG. 


\section{CONTINUUM Normal Pressure Hydrocephalus}

\section{KEY POINT}

- Pathologic CSF dynamics are an important part of the idiopathic normal pressure hydrocephalus pathophysiology. considered to predict good chances of improvement after surgery. ${ }^{54} \mathrm{~A}$ variant of this method is the ICP pulsatility curve, which describes how the pulse amplitude changes while ICP is manipulated to different levels during CSF infusion testing. ${ }^{42}$

\section{Shunt Patency Evaluation}

Either radionuclide shunt patency study or CSF infusion testing can be used to assess shunt function. ${ }^{39,55}$ Radionuclide shunt patency study involves the injection of a small volume of radioisotope into the shunt reservoir. Once the radionuclide is injected, images of the proximal system are obtained every minute for the first 20 minutes to create a time/activity curve, followed by imaging of the body region containing the distal shunt catheter. Determination of shunt patency involves demonstration of radionuclide in the peritoneal cavity or the venous system (for ventriculoatrial shunts). Other factors to consider include opening CSF pressure, rate of radionuclide outflow from the reservoir, and dispersal of radionuclide in the peritoneal cavity.

Shunt patency can also be determined by CSF infusion testing (Case 10-2). If the shunt is obstructed, then values of $R_{\text {out }}$ similar to those seen before shunt surgery will be found. On the other hand, if the shunt is functioning, the $\mathrm{R}_{\text {out }}$ will be much lower than the values seen before shunt surgery because the shunt facilitates CSF outflow and thus lowers the measured outflow resistance. ${ }^{56}$

\section{CONCLUSION}

iNPH is a common, treatable disorder that can be reliably diagnosed with an organized approach that incorporates diagnostic principles and procedures familiar to most neurologists, including a comprehensive history and physical examination, identification of key features on brain imaging, and assessment of the clinical response to tap test. Evidence supports the use of shunt surgery to treat patients with iNPH, and when patients are properly selected, the benefit-to-risk ratio is favorable. Neurologists have a role in the longitudinal care of patients with iNPH who have undergone shunt surgery, particularly in considering the differential diagnosis of any symptoms that may worsen after shunt surgery. Tertiary centers with expertise in complex iNPH are available throughout the world.

\section{REFERENCES}

1. Toma AK, Papadopoulos MC, Stapleton S, et al. Systematic review of the outcome of shunt surgery in idiopathic normal-pressure hydrocephalus. Acta Neurochir (Wien) 2013;155(10):1977-1980. doi:10.1007/s00701-013-1835-5.

2. Jaraj D, Rabiei K, Marlow T, et al. Prevalence of idiopathic normal-pressure hydrocephalus. Neurology 2014;82(16):1449-1454. doi:10.1212NNL.0000000000000342.

3. Tisell M, Höglund M, Wikkelsø C. National and regional incidence of surgery for adult hydrocephalus in Sweden. Acta Neurol Scand 2005;112(2):72-75. doi:10.1111/ j.1600-0404.2005.00451.x.

4. Census Reporter. censusreporter.org/ profiles/01000US-united-states/. Accessed February 5, 2016.

5. National Multiple Sclerosis Society. www. nationalmssociety.org/About-theSociety/MS-Prevalence. Accessed February 5, 2016.

6. Malm J, Eklund A. Idiopathic normal pressure hydrocephalus. Pract Neurol 2006;6:14-27. doi:10.1136/jnnp.2006.088351.

7. Relkin N, Marmarou A, Klinge $P$, et al. Diagnosing idiopathic normal-pressure hydrocephalus. Neurosurgery 2005; 57(3 suppl):S4-S16. doi:10.1227/ 01.NEU.0000168185.29659.C5.

8. Marmarou A, Bergsneider $M$, Klinge $P$, et al. The value of supplemental prognostic tests for the preoperative assessment of idiopathic normal-pressure hydrocephalus. Neurosurgery 2005;57(3 suppl):S17-S28. doi:10.1227/01.NEU.0000168184. 01002.60 . 
9. Mori E, Ishikawa M, Kato T, et al. Guidelines for management of idiopathic normal pressure hydrocephalus: second edition. Neurol Med Chir (Tokyo) 2012;52(11):775-809. doi:10.2176/nmc.52.775.

10. Nutt JG, Lang AE. Balance and gait disorders. Presented at: 63rd Annual Meeting of the American Academy of Neurology; 2011; Honolulu, Hawaii.

11. Stolze H, Kuhtz-Buschbeck JP, Drücke $H$, et al. Gait analysis in idiopathic normal pressure hydrocephalus - which parameters respond to the CSF tap test? Clin Neurophysiol 2000;111(9):1678-1686. doi:10.1016/ S1388-2457(00)00362-X

12. Nutt JG, Marsden CD, Thompson PD. Human walking and higher-level gait disorders, particularly in the elderly. Neurology 1993;43(2):268-279. doi:10.1212/ WNL.43.2.268.

13. Behrens A, Eklund A, Elgh E, et al. A computerized neuropsychological test battery designed for idiopathic normal pressure hydrocephalus. Fluids Barriers CNS 2014;11:22. doi:10.1186/2045-8118-11-22.

14. Thomas G, McGirt MJ, Woodworth G, et al. Baseline neuropsychological profile and cognitive response to cerebrospinal fluid shunting for idiopathic normal pressure hydrocephalus. Dement Geriatr Cogn Disord 2005;20(2-3):163-168.

15. Katzen $H$, Ravdin LD, Assuras $S$, et al. Postshunt cognitive and functional improvement in idiopathic normal pressure hydrocephalus. Neurosurgery 2011;68(2):416-419. doi:10.1227/NEU.0b013e3181ff9d01.

16. Hellström $P$, Klinge $P$, Tans J, Wikkelsø $C$. The neuropsychology of iNPH: findings and evaluation of tests in the European multicentre study. Clin Neurol Neurosurg 2012:114(2):130-134. doi:10.1016/ j.clineuro.2011.09.014

17. Israelsson $\mathrm{H}$, Allard $\mathrm{P}$, Eklund $\mathrm{A}$, Malm J. Symptoms of depression are common in patients with idiopathic normal pressure hydrocephalus: the INPH-CRasH study. Neurosurgery 2016;78(2):161-168. doi:10.1227/NEU.0000000000001093.

18. Sakakibara R, Kanda T, Sekido T, et al. Mechanism of bladder dysfunction in idiopathic normal pressure hydrocephalus. Neurourol Urodyn 2008;27(6):507-510. doi:10.1002/nau.20547.

19. Williams MA, Relkin NR. Diagnosis and management of idiopathic normal pressure hydrocephalus. Neurol Clin Pract 2013:3(5):375-385. doi:10.1212/CPJ. 0b013e3182a78f6b.
20. Osborn AG, Salzman KL, Barkovich AJ Diagnostic imaging. Brain. 2nd ed. Salt Lake City: Amirsys Publishing Inc, 2010.

21. Hashimoto $M$, Ishikawa $M$, Mori $E$, Kuwana N; Study of INPH on neurological improvement (SINPHONI). Diagnosis of idiopathic normal pressure hydrocephalus is supported by MRI-based scheme: a prospective cohort study. Cerebrospinal Fluid Res 2010;7:18. doi:10.1186/ 1743-8454-7-18.

22. Ringstad G, Emblem KE, Geier O, et al. Aqueductal stroke volume: comparisons with intracranial pressure scores in idiopathic normal pressure hydrocephalus. AJNR Am J Neuroradiol 2015;36(9):1623-1630. doi:10.3174/ajnr.A4340.

23. Malm J, Graff-Radford NR, Ishikawa M, et al. Influence of comorbidities in idiopathic normal pressure hydrocephalus - research and clinical care. A report of the ISHCSF task force on comorbidities in INPH. Fluids Barriers CNS 2013;10(1):22. doi:10.1186/2045-8118-10-22.

24. Halperin JJ, Kurlan R, Schwalb JM, et al. Practice guideline: Idiopathic normal pressure hydrocephalus: Response to shunting and predictors of response. Report of the Guideline Development, Dissemination, and Implementation Subcommittee of the American Academy of Neurology. Neurology 2015;85:2063-2071.

25. Tudor KI1, Tudor M, McCleery J, Car J. Endoscopic third ventriculostomy (ETV) for idiopathic normal pressure hydrocephalus (iNPH). Cochrane Database Syst Rev 2015;7:CD010033. doi:10.1002/ 14651858.CD010033.pub2.

26. Sankey EW, Jusué-Torres I, Elder BD, et al. Functional gait outcomes for idiopathic normal pressure hydrocephalus after primary endoscopic third ventriculostomy. J Clin Neurosci 2015;22(8):1303-1308. doi:10.1016/j. jocn.2015.02.019.

27. Williams MA. The trouble with " $n$ " in normal-pressure hydrocephalus. Neurology 2014;82(15):1350. doi:10.1212/ WNL.0000000000000325.

28. Alperin N, Oliu CJ, Bagci AM, et al. Low-dose acetazolamide reverses periventricular white matter hyperintensities in iNPH. Neurology 2014;82(15):1347-1351. doi:10.1212/ WNL.0000000000000313.

29. Bergsneider $M$, Black $P M$, Klinge $P$, et al. Surgical management of idiopathic normal-pressure hydrocephalus. Neurosurgery 2005;57(3 suppl):S29-S39. doi:10.1227/ 01.NEU.0000168186.45363.4D. 


\section{CONTINUUM Normal Pressure Hydrocephalus}

30. Wikkelsø C, Hellström P, Klinge PM, Tans JT; European iNPH Multicentre Study Group. The European iNPH Multicentre Study on the predictive values of resistance to CSF outflow and the CSF Tap Test in patients with idiopathic normal pressure hydrocephalus. J Neurol Neurosurg Psychiatry 2013;84(5):562-568. doi:10.1136/ jnnp-2012-303314.

31. He Y, Murphy RK, Roland JL, Limbrick DD Jr. Interactions between programmable shunt valves and the iPad 3 with Smart Cover. Childs Nerv Syst 2013:29(4):531-533. doi:10.1007/s00381-013-2053-4.

32. Lavinio A, Harding S, Van Der Boogaard F, et al. Magnetic field interactions in adjustable hydrocephalus shunts. J Neurosurg Pediatr 2008;2(3):222-228. doi:10.3171/PED/ 2008/2/9/222.

33. Spader HS, Ratanaprasatporn L, Morrison JF, et al. Programmable shunts and headphones: are they safe together? J Neurosurg Pediatr 2015;16(4):402-405. doi:10.3171/ 2015.1.PEDS14400.

34. Shellock FG. Mrisafety.com: your information resource for MRI safety, bioeffects, \& patient management. www.mrisafety.com. Accessed February 5, 2016

35. Aschoff A, Kremer $P$, Hashemi B, Kunze $S$. The scientific history of hydrocephalus and its treatment. Neurosurg Rev 1999;22(2-3): 67-93. doi:10.1007/s101430050035.

36. Goodwin CR, Kharkar S, Wang P, et al. Evaluation and treatment of patients with suspected normal pressure hydrocephalus on long-term warfarin anticoagulation therapy. Neurosurgery 2007;60(3): 497-501. doi:10.1227/01.NEU. 0000255349.71700.E1.

37. Lim HW, Shim BS, Yang CJ, et al. Hearing loss following ventriculoperitoneal shunt in communicating hydrocephalus patients: a pilot study. Laryngoscope 2014;124(8): 1923-1927. doi:10.1002/lary.24553.

38. American Medical Association. Current procedural terminology (CPT) 2015. Chicago: American Medical Association Press, 2015.

39. Kharkar S, Shuck J, Kapoor S, et al. Radionuclide shunt patency study for evaluation of suspected ventriculoperitoneal shunt malfunction in adults with normal pressure hydrocephalus. Neurosurgery 2009;64(5):909-918. doi:10.1227/ 01.NEU.0000343545.93153.EB

40. Eklund A, Smielewski P, Chambers I, et al. Assessment of cerebrospinal fluid outflow resistance. Med Biol Eng Comput 2007;45(8): 719-735. doi:10.1007/s11517-007-0199-5.
41. Malm J, Jacobsson J, Birgander R, Eklund A Reference values for CSF outflow resistance and intracranial pressure in healthy elderly. Neurology 2011;76(10):903-909. doi:10.1212/WNL.0b013e31820f2dd0.

42. Qvarlander S, Lundkvist B, Koskinen LO, et al. Pulsatility in CSF dynamics: pathophysiology of idiopathic normal pressure hydrocephalus. J Neurol Neurosurg Psychiatry 2013;84(7): 735-741. doi:10.1136/jnnp-2012-302924.

43. Kim DJ, Kim H, Kim YT, et al. Thresholds of resistance to CSF outflow in predicting shunt responsiveness. Neurol Res 2015;37(4):332-340. doi:10.1179/ $1743132814 Y .0000000454$.

44. Malm J, Sundström N, Cesarini KG, et al. Implementation of a new CSF dynamic device: a multicenter feasibility study in 562 patients. Acta Neurol Scand 2012;125(3):199-205. doi:10.1111/j.1600-0404.2011.01533.x.

45. McGirt MJ, Woodworth G, Coon AL, et al. Diagnosis, treatment, and analysis of long-term outcomes in idiopathic normal-pressure hydrocephalus. Neurosurgery 2005;57(4):699-705. doi:10.1227/01.NEU.0000175724.00147.10.

46. Tinetti ME. Performance-oriented assessment of mobility problems in elderly patients. J Am Geriatr Soc 1986;34(2):119-126.

47. Podsiadlo D, Richardson S. The timed "Up \& Go": a test of basic functional mobility for frail elderly persons. J Am Geriatr Soc 1991;39(2):142-148.

48. Greenberg BM, Williams MA. Infectious complications of temporary spinal catheter insertion for diagnosis of adult hydrocephalus and idiopathic intracranial hypertension. Neurosurgery 2008;62(2):431-436. doi:10.1227/01.neu.0000316010.19012.35.

49. Marmarou A, Young HF, Aygok GA, et al. Diagnosis and management of idiopathic normal-pressure hydrocephalus: a prospective study in 151 patients. J Neurosurg 2005;102(6):987-997.

50. Nornes H, Rootwelt K, Sjaastad O. Normal pressure hydrocephalus. Long-term intracranial pressure recording. Eur Neurol 1973;9(5):261-274.

51. Børgesen SE, Gjerris F. The predictive value of conductance to outflow of CSF in normal pressure hydrocephalus. Brain 1982;105(pt 1): 65-86. doi:10.1093/brain/105.1.65.

52. Williams MA, Razumovsky AY, Hanley DF. Comparison of Pcsf monitoring and controlled CSF drainage diagnose normal pressure hydrocephalus. Acta Neurochir Suppl 1998;71 328-330. doi:10.1007/978-3-7091-6475-4_95. 
53. Eide PK, Sorteberg W. Diagnostic intracranial pressure monitoring and surgical management in idiopathic normal pressure hydrocephalus: a 6-year review of 214 patients. Neurosurgery 2010;66(1):80-91. doi:10.1227/01.NEU. 0000363408.69856.B8.

54. Eide PK, Brean A. Cerebrospinal fluid pulse pressure amplitude during lumbar infusion in idiopathic normal pressure hydrocephalus can predict response to shunting. Cerebrospinal Fluid Res 2010;7:5. doi:10.1186/1743-8454-7-5.
55. Eklund A, Lundkvist B, Koskinen LO, Malm J. Infusion technique can be used to distinguish between dysfunction of a hydrocephalus shunt system and a progressive dementia. Med Biol Eng Comput 2004;42(5):644-649. doi:10.1007/ BF02347546.

56. Malm J, Lundkvist B, Eklund A, et al. CSF outflow resistance as predictor of shunt function. A long-term study. Acta Neurol Scand 2004;110(3):154-160. doi:10.1111/ j.1600-0404.2004.00302.x. 